\title{
How well prepared are medical students for their first year as doctors? The views of consultants and specialist registrars in two teaching hospitals
}

\author{
C Matheson, D Matheson
}

- Additional tables are published online only at http:// postgradmedj.com/content/ vol85/issue1009

Medical Education Unit, University of Nottingham, Queens Medical Centre, Nottingham \& East Midlands Healthcare Workforce Deanery, Nottingham, UK:

catherine.matheson@ nottingham.ac.uk

Correspondence to: Dr D Matheson, Medical Education Unit, University of Nottingham, Queens Medical Centre, Nottingham NG7 2UH, UK; david.matheson@ nottingham.ac.uk

Received 14 May 2008 Accepted 4 July 2009

\begin{abstract}
Objective: To evaluate (1) the extent to which first year doctors (foundation year 1 doctors, F1s) in two teaching hospitals in the Trent Deanery were rated by specialist registrars (SpRs) and consultants as being well prepared for practice; (2) the importance ascribed by SpRs and consultants to the various items of core knowledge, skills and attitudes outlined in the publication of the General Medical Council, Tomorrow's Doctors.
\end{abstract}

Method: SpRs and consultants were asked to rate: how well prepared F1s were in a range of items of core knowledge, skills and attitudes that a new medical graduate must possess as outlined in Tomorrow's Doctors; the importance for a new doctor of each item of core knowledge, skills and attitudes; and how well the medical school had prepared F1s in respect of key generic issues related to their practice.

Results: In most of the items of core knowledge, skills and attitudes covering 8 of the 11 topic areas of Tomorrow's Doctors, F1s were seen as not prepared for starting work, especially in regard to clinical and practical skills and the more challenging communication skills. They were best prepared in asking for help and in basic communication skills.

Conclusions: Overall, F1s in the study were not well prepared either to perform the tasks that await them or in terms of most of the specific background knowledge and skills necessary for the successful execution of those tasks. The level of preparedness raises important issues about medical training and transition from medical graduate to first year doctor. Further research is needed to determine whether this situation exists in other regions of the UK.

Over a century ago concerns were raised that medical graduates were not well prepared for practice, especially in terms of clinical and practical skills. ${ }^{5}$ Such concerns are still ongoing worldwide ${ }^{7-9}$ and in the UK. ${ }^{10}{ }^{11}$ In the latter context, Tomorrow's Doctors $^{12}$ sought to address them. However, although improvements were underlined in general preparedness, ${ }^{12} 13$ communicating skills ${ }^{6}$ and teamwork, ${ }^{14}$ deficiencies in clinical and practical skills remained a major concern, ${ }^{15-18}$ as did deficiencies in prescribing, ${ }^{1920}$ self confidence, ${ }^{31521}$ and in acute care, leading to increased stress and errors made by junior doctors. ${ }^{18}$ In their survey of more than 5000 pre-registration house officers (PRHOs) on how well they thought that medical school had prepared them for practice, Goldacre et a ${ }^{22}$ found wide variations and substantial differences among medical schools.

Most of the recent worldwide ${ }^{7-9}$ and UK research into the transition from medical graduate to first year trainee doctor has examined the self perceptions of preparedness of medical graduates in their first year of training, $3151620-22$ often focusing only on a particular aspect of preparedness, such as acute care, ${ }^{18}$ knowledge of pharmacology ${ }^{20}$ or communication skills. ${ }^{17}$ A small number of studies have investigated the perceptions of preparedness of medical graduates according to educational supervisors, ${ }^{17}{ }^{23}$ to both consultants and PRHOs, ${ }^{14}$ and to both educational supervisors and PRHOs. ${ }^{12} 13$

Jones et $a l^{12}$ and Wall et al ${ }^{14}$ examined the perceptions of educational supervisors and consultants about the preparedness for practice of PRHOs; they found them least prepared in clinical and practical skills such as treatment, prescribing, emergencies, and decision making, and best prepared in working as a team, ${ }^{12}{ }^{14}$ awareness of their own limitations, ${ }^{12}$ history taking, and communicating with parents and relatives. ${ }^{14}$ Jones et a ${ }^{12}$ measured 18 broad competencies and 14 specific competencies. Wall et a ${ }^{14}$ only surveyed 17 basic subject areas. Although Jones et al ${ }^{12}$ surveyed a broader range of competencies than did Wall et al ${ }^{14}$ they did not carry out formal statistical analysis in comparing the responses of educational supervisors and PRHOs. Both these studies rated PRHOs in terms of competencies to be achieved at the end of the PRHO year-as outlined in The New Doctor ${ }^{24}$-rather than in terms of competencies that had to be acquired in order to become a medical graduate-as outlined in Tomorrow's Doctors. ${ }^{2}$

A handful of studies have investigated the preparedness for practice of foundation year 1 doctors (F1s) rather than PRHOs. ${ }^{3}{ }^{20}$ However, the present study is the first to have surveyed both consultants and specialist registrars (SpRs) about preparedness for practice of F1s, or even of PRHOs, in relation to competencies outlined in Tomorrow's Doctors. ${ }^{2}$ It is also the first to ask consultants and SpRs to rate the importance of each of these competencies for a new doctor.

The reduction in working hours following the European Working Time Directive and the changing structures in the National Health Service have reduced the contact and interaction between foundation doctors and consultants, and consequently the views of $\mathrm{SpRs}$ are becoming increasingly important as they are arguably in a better position than consultants to comment on the competencies of F1s. Comparing the views of both consultants and SpRs will permit a meaningful overview of the preparedness for practice of medical graduates. 


\section{Tomorrow's Doctors}

The UK General Medical Council (GMC) inspects, regulates and licenses medical schools. Tomorrow's Doctors ${ }^{1}$ published by the GMC in 1993 set up a framework of recommended knowledge, skills, attitudes and behaviours expected of newly qualified medical graduates. Clinical and practical skills, critical thinking and communication skills were emphasised. Tomorrow's Doctors ${ }^{2}$ published by the GMC in 2003 further emphasised communication skills and critical thinking as well as continuing professional development, multiprofessional learning and the importance of outcome based learning.

Tomorrow's Doctors ${ }^{12}$ set up recommendations about the minimum requirements for the undergraduate medical curriculum. The recommended curricular content contains 108 topics, categorised into 11 curricular themes (scientific basis of practice, treatment, clinical and practical skills, communication skills, general skills, teaching skills, working environment, medico-legal and ethical issues, disability and rehabilitation, the health of the public, the individual and society).

Using formal statistical means, the present study aimed:

- to survey consultants and SpRs in two teaching hospitals in the Trent Deanery in the East Midlands of England about the preparedness for practice of their F1s in relation to 73 out of 108 topics, covering eight of 11 curricular themes from Tomorrow's Doctors ${ }^{2}$

- to rate how important each of these competencies is for a new doctor

- to triangulate the preparedness in these competencies with generic questions not directly derived from Tomorrow's Doctors.

\section{METHODS}

\section{Questionnaire design}

Out of 91 questions, 73 were drawn directly from Tomorrow's Doctors $^{2}$ and covered eight of 11 curricular themes. The curricular themes of scientific basis of practice, treatment, clinical and practical skills, communication skills, and medicolegal and ethical issues were covered in the survey. In order to limit the size of the questionnaire, the curricular themes of the working environment, general skills, and teaching skills were partially surveyed and aggregated into one category for analysis. Respondents were asked to rate how well prepared F1s were in each of these areas, using a five point Likert response (ranging from $5=$ well prepared to $1=$ poorly prepared, with an additional box for don't know).

In addition, the questionnaire contained 18 questions on generic competencies. Although these were not taken directly from the curricular themes, some of them covered competencies dealt with in the first part of the questionnaires. For example, respondents were asked directly how well medical school had prepared the F1s in terms of overall knowledge, theoretical knowledge, basic science knowledge, clinical practice, and technical skills. These generic questions were phrased differently from those on the related topics, which appeared earlier in the questionnaire, in order to reduce bias due to acquiescence effect $^{26}$ and maximise the internal consistency, validity and reliability of the data. ${ }^{27}$ Respondents were asked to indicate the extent of their agreement by means of five point Likert items (ranging from $5=$ strongly agree to $1=$ strongly disagree).

\section{The Foundation Programme}

Introduced in 2005, the Foundation Programme is a 2 year generic training programme which forms the bridge between medical school and specialist/general practice training. ${ }^{3}$ It is designed to give trainees a broader range of experience before choosing an area of medicine in which to specialise. ${ }^{3}$ All foundation trainees are attached to an educational supervisor who is responsible for maintaining an overview of the trainee's progress. "The Foundation Programme Curriculum shows how educational practice can support the first two years of professional development after medical school."4

Only after successfully passing the foundation year 1 (FY1) is a doctor fully registered with the General Medical Council. The FY1 was previously known as the pre-registration house officer, or PRHO, year. ${ }^{3}$

A draft of the questionnaire was evaluated by a group of three senior faculty members from the Nottingham Medical School and the Trent Deanery. They suggested asking respondents to rate the importance for a new doctor of each of the 73 curricular themes on a five point Likert scale (from $5=$ very important to $1=$ very unimportant). They also suggested a question on the extent to which foundation doctors had "the confidence to challenge decisions concerning immediate patient management made by seniors away from the patient". A second draft was piloted with a group of three consultants and four specialist registrars. They proposed a question about how well medical school had prepared F1s "to seek help from more experienced colleagues". All these suggestions were incorporated into the revised questionnaire.

\section{Selection of respondents}

In early 2007, when F1s had done on average 6 of their 12 months before being fully registered with the GMC, questionnaires were sent to all consultants and SpRs who took on F1s in two teaching hospitals in the Trent Deanery in the East Midlands. SpRs and consultants (and their equivalents) in general practice, psychiatry, ophthalmology and anaesthetics were not included in the research as their specialisms did not, at that time, take F1s. The two hospitals selected were the largest in the Trent Deanery. Between them, they accounted for approximately $40 \%$ of the SpRs and consultants in the Deanery and hired a greater percentage of Nottingham medical graduates than did the district hospitals. The questionnaires were sent as hard copy with an introductory letter describing the aims of the study. The study provided the opportunity for anonymity although this meant that non-responders could not be followed up. Nonetheless, the questionnaires were sent again by email to all consultants and SpRs who worked with F1s, thanking those who had responded and reminding those who had not responded to do so. This elicited a few more responses. There was no possibility of identifying any individual if respondents returned the hard copy of the questionnaire without indicating their names. Around $80 \%$ of the responses were anonymous and were returned as hard copy. To enhance the anonymity of the questionnaire, demographic data were not sought. Respondents were only asked in which specialty they worked. This was done in order to ascertain whether the sample would be representative of medicine and surgery in the two hospitals. 
Table 1 Mean scores on curricular themes of Tomorrow's Doctors's: preparedness of F1s and importance of curricular theme

\begin{tabular}{|c|c|c|c|c|}
\hline \multirow[b]{2}{*}{ Curricular theme } & \multicolumn{2}{|c|}{ Preparedness } & \multicolumn{2}{|l|}{ Importance } \\
\hline & $\begin{array}{l}\text { SpRs (SD) } \\
\text { Rank }\end{array}$ & $\begin{array}{l}\text { Consultants (SD) } \\
\text { Rank }\end{array}$ & $\begin{array}{l}\text { SpRs (SD) } \\
\text { Rank }\end{array}$ & $\begin{array}{l}\text { Consultants (SD) } \\
\text { Rank }\end{array}$ \\
\hline \multirow{2}{*}{$\begin{array}{l}\text { General skills, teaching skills, and } \\
\text { working environment* ( } 5 \text { items) }\end{array}$} & $3.40(0.80)$ & $3.51(0.87)$ & $4.55(0.52)$ & $4.61(0.42)$ \\
\hline & 1st & $1 \mathrm{st}$ & $1 \mathrm{st}$ & $1 \mathrm{st}$ \\
\hline \multirow[t]{2}{*}{ Clinical and practical skills (20 items) } & $2.88(0.81)$ & $2.82(0.80)$ & $4.23(0.61)$ & $4.26(0.42)$ \\
\hline & 2nd & 4th & 2nd & 2nd \\
\hline \multirow{2}{*}{$\begin{array}{l}\text { Medico-legal and ethical issues (12 } \\
\text { items) }\end{array}$} & $2.87(0.69)$ & $2.92(0.85)$ & $4.01(0.85)$ & $4.10(0.61)$ \\
\hline & $3 r d$ & $3 r d$ & $3 r d$ & $3 r d$ \\
\hline \multirow[t]{2}{*}{ Communication skills (11 items) } & $2.84(0.86)$ & $2.98(0.87)$ & $3.83(0.58)$ & $3.88(0.46)$ \\
\hline & 4th & 2nd & 6th & 6th \\
\hline \multirow{2}{*}{$\begin{array}{l}\text { The scientific basis of practice (10 } \\
\text { items) }\end{array}$} & $2.73(0.62)$ & $2.75(0.71)$ & $3.88(0.53)$ & $4.04(0.41)$ \\
\hline & 5th & 5th & 5th & 4th \\
\hline \multirow[t]{2}{*}{ Treatment (12 items) } & $2.68(0.71)$ & $2.61(0.67)$ & $3.90(0.56)$ & $3.94(0.44)$ \\
\hline & 6th & 6th & 4th & 5th \\
\hline $\begin{array}{l}\text { Overall from } 70 \text { items (questions } 48-50 \\
\text { eliminated }\end{array}$ & $2.87(0.62)$ & $2.86(0.66)$ & $4.13(0.51)$ & $4.19(0.34)$ \\
\hline
\end{tabular}

F1s, foundation year 1 doctors; SpRs, specialist registrars.

${ }^{*}$ As they were only partially surveyed, general skills, teaching skills, and working environment were aggregated into one category.

\section{Data analysis and statistics}

Answers were coded into an Excel spreadsheet and data analysed with SPSS 15.0 to generate descriptive statistics comprising mean, standard deviation (SD) and range, while Mann-Whitney U and Wilcoxon signed rank tests were used to compare between groups and sets of responses. ${ }^{28}$ Tests of reliability and internal consistency of the data were carried out using Cronbach's $\alpha^{27}$ The data were aggregated across each curricular theme of Tomorrow's Doctors ${ }^{2}$ and across some subthemes to enable comparisons and for Spearman rank correlations to be carried out across themes. As foundation doctors have to undertake workplace based assessments (DOPSdirectly observed procedural skills; mini-CEX_clinical evaluation exercise; and $\mathrm{CbD}$-case based discussion), all the practical clinical skills and communication skills outlined in Tomorrow's Doctors ${ }^{2}$ were examined.

For questions on preparedness, piloting the questionnaire indicated that 4 was taken to mean "prepared", 2 "unprepared", with 3 as a midpoint point between "prepared" and "unprepared". ${ }^{29}$ This meaning was adopted in analysis and 6 "don't know" was discounted. For questions on importance, piloting indicated that 4 was taken as "important", 2 as "unimportant", with 3 as being a midpoint point between "important" and "unimportant". ${ }^{29}$ This meaning was adopted in analysis and 6 "don't know" was discounted. For questions not derived from the curricular themes of Tomorrow's Doctors, ${ }^{2}$ piloting indicated that 4 was taken as "agree" and 2 as "disagree", with 3 as the midpoint between "agree" and "disagree". This meaning was adopted in analysis.

\section{RESULTS}

From 443 questionnaires sent out (238 and 205), 107 were returned by consultants ( $45 \%$ return) and 121 were returned by SpRs (59\% return).

Thirty-two per cent (34/107) of consultants indicated their specialism and of these half $(17 / 107)$ were in either medicine or surgery. Thirty-six per cent $(43 / 121)$ of SpRs indicated their specialism and of these $79 \%$ (34/43) were in medicine and $21 \%$ $(9 / 43)$ were in surgery. Overall, $66 \%$ of respondents who indicated their specialism were in medicine, and $34 \%$ in surgery.

Table 2 Correlations of perceptions of preparedness of F1s across the curricular themes

\begin{tabular}{|c|c|c|c|c|c|c|}
\hline & $\begin{array}{l}\text { Scientific basis of } \\
\text { practice }\end{array}$ & Treatment & $\begin{array}{l}\text { Clinical and } \\
\text { practical skills }\end{array}$ & $\begin{array}{l}\text { Communication } \\
\text { skills (10 items) }\end{array}$ & $\begin{array}{l}\text { General skills, } \\
\text { teaching skills and } \\
\text { working } \\
\text { environment }\end{array}$ & $\begin{array}{l}\text { Medico-legal and } \\
\text { ethical issues }\end{array}$ \\
\hline Curricular theme & $\begin{array}{l}\rho \\
\text { Sig }(2 \text { tailed })\end{array}$ & $\begin{array}{l}\rho \\
\text { Sig }(2 \text { tailed })\end{array}$ & $\stackrel{\rho}{\text { Sig }(2 \text { tailed })}$ & $\stackrel{\rho}{\text { Sig }(2 \text { tailed })}$ & $\begin{array}{l}\rho \\
\text { Sig (2 tailed) }\end{array}$ & $\begin{array}{l}\rho \\
\text { Sig (2 tailed) }\end{array}$ \\
\hline \multirow[t]{2}{*}{ The scientific basis of practice } & 1.000 & 0.555 & 0.412 & 0.343 & 0.466 & 0.366 \\
\hline & & 0.000 & 0.000 & 0.000 & 0.000 & 0.000 \\
\hline \multirow[t]{2}{*}{ Treatment } & 0.555 & 1.000 & 0.691 & 0.531 & 0.611 & 0.443 \\
\hline & 0.000 & & 0.000 & 0.000 & 0.000 & 0.000 \\
\hline \multirow[t]{2}{*}{ Clinical and practical skills } & 0.412 & 0.691 & 1.000 & 0.496 & 0.644 & 0.477 \\
\hline & 0.000 & 0.000 & & 0.000 & 0.000 & 0.000 \\
\hline \multirow[t]{2}{*}{ Communication skills } & 0.343 & 0.531 & 0.496 & 1.000 & 0.683 & 0.574 \\
\hline & 0.000 & 0.000 & 0.000 & & 0.000 & 0.000 \\
\hline \multirow{2}{*}{$\begin{array}{l}\text { General skills, teaching skills and } \\
\text { working environment }\end{array}$} & 0.466 & 0.611 & 0.644 & 0.683 & 1.000 & 0.607 \\
\hline & 0.000 & 0.000 & 0.000 & 0.000 & & 0.000 \\
\hline \multirow[t]{2}{*}{ Medico-legal and ethical issues } & 0.366 & 0.443 & 0.477 & 0.574 & 0.607 & 1.000 \\
\hline & 0.000 & 0.000 & 0.000 & 0.000 & 0.000 & \\
\hline
\end{tabular}

F1s, foundation year 1 doctors; Sig, significance. All correlations are significant at the 0.01 level (2 tailed). 
Table 3 Correlations of perceptions of importance across the curricular themes

\begin{tabular}{|c|c|c|c|c|c|c|}
\hline & $\begin{array}{l}\text { The scientific } \\
\text { basis of practice }\end{array}$ & Treatment & $\begin{array}{l}\text { Clinical and } \\
\text { practical skills }\end{array}$ & $\begin{array}{l}\text { Communication } \\
\text { skills [10 items] }\end{array}$ & $\begin{array}{l}\text { General skills, } \\
\text { teaching skills and } \\
\text { working } \\
\text { environment }\end{array}$ & $\begin{array}{l}\text { Medico-legal anc } \\
\text { ethical issues }\end{array}$ \\
\hline \multirow[t]{2}{*}{ The scientific basis of practice } & 1.000 & 0.569 & 0.529 & 0.434 & 0.313 & 0.450 \\
\hline & & 0.000 & 0.000 & 0.000 & 0.000 & 0.000 \\
\hline \multirow[t]{2}{*}{ Clinical and practical skills } & 0.529 & 0.537 & 1.000 & 0.583 & 0.417 & 0.602 \\
\hline & 0.000 & 0.000 & & 0.000 & 0.000 & 0.000 \\
\hline \multirow[t]{2}{*}{ Communication skills } & 0.434 & 0.640 & 0.583 & 1.000 & 0.581 & 0.590 \\
\hline & 0.000 & 0.000 & 0.000 & & 0.000 & 0.000 \\
\hline $\begin{array}{l}\text { General skills, teaching skills and } \\
\text { working environment }\end{array}$ & 0.313 & 0.463 & 0.417 & 0.581 & 1.000 & 0.590 \\
\hline
\end{tabular}

Sig, significance. All correlations are significant at the 0.01 level (2 tailed).

Questions on British sign language, Makhaton and the deafblind manual (questions 48, 49 and 50) were answered by only 30 respondents-13\% of those who returned the questionnaire-and were excluded from further analysis. Using Cronbach's $\alpha$, the internal consistency of the responses to questions 1-73 (minus questions 48-50) was very high with 0.984 (preparedness) and 0.956 (importance). For consultants it was 0.996 (preparedness) and 0.927 (importance), while for $\mathrm{SpRs}$ it was 0.945 (preparedness) and 0.968 (importance). A number of 0.7 , or above, indicates satisfactory internal consistency and reliability. ${ }^{30}$

\section{Curricular themes of Tomorrow's Doctors: preparedness and importance}

When considered in terms of the curricular themes, there were no statistically significant differences between the SpRs and consultants, whether in their views of F1s' preparedness for practice or in their perceptions of the importance of the curricular themes. Only the aggregated curricular theme of "general skills, teaching skills and working environment" was rated above the midpoint of 3 for preparedness. Table 1 illustrates just how close the SpRs and consultants were in perceptions.

Table 4 Items with means between 3 and 4 in preparedness, in rank order

\begin{tabular}{|c|c|c|c|c|}
\hline \multirow[b]{2}{*}{ Rank/item } & \multicolumn{2}{|c|}{ Preparedness } & \multicolumn{2}{|c|}{ Importance } \\
\hline & Mean & SD & Mean & SD \\
\hline 1. 061 Recognising personal and professional limits and willingness to ask for help if necessary & 3.85 & 1.11 & 4.70 & 0.60 \\
\hline 3. 043 Communicate sensitively clearly and effectively with patients and their relatives & 3.71 & 0.95 & 4.69 & 0.60 \\
\hline 4. 057 Working as part of a team & 3.65 & 1.07 & 4.69 & 0.62 \\
\hline 5. 065 Maintaining confidentiality & 3.63 & 1.01 & 4.51 & 0.77 \\
\hline 8. 058 Taking proper account of ethical considerations and the probity required of a doctor & 3.49 & 1.05 & 4.56 & 0.67 \\
\hline 9. 071 Knowing who is the most appropriate person to ask for consent & 3.42 & 1.09 & 4.22 & 0.89 \\
\hline 10. 024 Perform a full physical examination, and a mental-state examination & 3.39 & 1.15 & 4.79 & 0.54 \\
\hline 11. 032 Insert a cannula into a peripheral vein & 3.33 & 1.17 & 4.42 & 0.80 \\
\hline 12. 045 Communicate sensitively clearly and effectively with nursing colleagues & 3.32 & 1.09 & 4.67 & 0.67 \\
\hline 13. 062 Making sure that patients' rights are protected & 3.28 & 1.07 & 4.33 & 0.78 \\
\hline 17. 01 Understanding of the basic clinical, behavioural and social sciences upon which medical is based. & 3.15 & 0.95 & 4.37 & 0.65 \\
\hline 18. 012 Taking account of a patient's own views and beliefs when suggesting treatment options & 3.15 & 1.25 & 4.16 & 10.00 \\
\hline $\begin{array}{l}\text { 19. } 020 \text { Knowledge about and understanding of the role that lifestyle, including diet and nutrition, can play in } \\
\text { promoting health and preventing disease }\end{array}$ & 3.09 & 0.97 & 3.64 & 0.96 \\
\hline 20. 030 Write safe prescriptions for different types of drugs (practical clinical skills) & 3.04 & 1.21 & 4.71 & 0.61 \\
\hline $\begin{array}{l}\text { 21. } 08 \text { Understand normal and abnormal structure and function in terms of disease presentation and response } \\
\text { to illness }\end{array}$ & 3.02 & 1.00 & 4.52 & 0.65 \\
\hline 22. 060 Keeping medical knowledge up to date and determining personal learning needs & 3.02 & 1.11 & 4.39 & 0.73 \\
\hline
\end{tabular}


Table 5 Items with means below 2 in preparedness, in rank order

\begin{tabular}{llllll}
\hline \multirow{2}{*}{ Item } & \multicolumn{2}{c}{ Preparedness } & & \multicolumn{2}{c}{ Importance } \\
\cline { 2 - 3 } \cline { 5 - 6 } & Mean & SD & & Mean & SD \\
\hline $\begin{array}{l}\text { O41 Insert a nasogastric } \\
\text { tube* }\end{array}$ & 1.95 & 1.04 & & 3.61 & 1.17 \\
036 Perform suturing & 1.92 & 1.00 & & 3.29 & 1.20
\end{tabular}

*In the post-consultation draft of the third edition of Tomorrow's Doctors, ${ }^{31}$ "insert a nasogastric tube" no longer features although it was included in the draft issued for consultation. ${ }^{32}$

When the consultants and SpRs were considered as a single group, Spearman rank correlations across the curricular themes showed correlations significant at the 0.01 level (two tailed) in terms of both preparedness and importance, as shown in tables 2 and 3 .

\section{Highest and lowest scoring topics according to Tomorrow's Doctors}

As there was only one statistically significant difference between SpRs and consultants as regards the preparedness of the F1s in terms of the topics from Tomorrow's Doctors (question 17 "knowledge and understanding of rehabilitation and care within institutions and the community" - consultants' mean $(\mathrm{SD})=2.88$ (0.92); SpRs' mean $(\mathrm{SD})=2.07$ (0.84); $\mathrm{p}<0.0001$ on Mann-Whitney U test), for the remainder of this paper we shall treat the two groups of respondents together. The supplemental tables detail how the SpRs and consultants differ, or concur, in their perceptions.

In terms of preparedness, all the items had a range of 1-5, which, taken with the high levels of internal consistency, indicates that some F1s were seen overall as being very well prepared and others very unprepared. There are no items with means above 4 in preparedness, but one item in the generic questions (question 79 "They are well prepared to seek help from more experienced colleagues") had a mean (SD) of 4.04 (0.85). Table 4 shows those items with means between 3 and 4 in preparedness, in rank order, while table 5 shows those items whose mean for preparedness was $<2$.

From this, it is clear that, of 70 items analysed, F1s were rated at $<3$ (unprepared/very unprepared) in 48 of them.

\section{Clinical and practical skills from Tomorrow's Doctors}

As clinical and practical skills are not only the very stuff of the new doctor's work but are also the focus of the various workplace based assessments that foundation doctors have to undertake in the course of the Foundation Programme, it is perhaps appropriate to show them in order of preparedness (table 6).

\section{Communication skills from Tomorrow's Doctors}

It is clear from table 7 that the more difficult the conversation, the less the level of preparedness. This is perhaps not unreasonable as the new F1s are likely to have had little opportunity to acquire the skills necessary for difficult conversations and to use them outside of a practice scenario.

\section{Comparison between Tomorrow's Doctors questions and generic questions}

The minor semantic difference between asking for level of agreement/disagreement with the statement in, for example, question 79, and asking for the perception of the degree of preparedness regarding question 61 has to be acknowledged, though such high levels of correlations between relevant responses support their use here.

When asked directly in questions $74 / 75$ how well medical school had prepared F1s, SpRs and consultants gave much higher ratings than they did for the curricular theme of scientific basis of practice (aggregated questions $1-10)(p<0.0005)$, as can be seen in table 8 . There is no statistically significant difference between the results for question 76 and those for clinical and practical skills (questions 23-42) or clinical skills (questions 2330). Equally there is no statistically significant difference

Table 6 Preparedness of F1s in clinical and practical skills in rank order, and importance of each skill

\begin{tabular}{|c|c|c|c|c|}
\hline \multirow[b]{2}{*}{ Rank/item } & \multicolumn{2}{|c|}{ Preparedness } & \multicolumn{2}{|c|}{ Importance } \\
\hline & Mean & SD & Mean & SD \\
\hline 1. 023 Take and record a patient's history, including their family history & 3.79 & 1.16 & 4.69 & 0.71 \\
\hline 2. 031 Carry out venepuncture & 3.57 & 1.17 & 4.39 & 0.83 \\
\hline 3. 024 Perform a full physical examination, and a mental-state examination & 3.39 & 1.15 & 4.79 & 0.54 \\
\hline 4. 032 Insert a cannula into a peripheral vein & 3.33 & 1.17 & 4.42 & 0.78 \\
\hline 5. 037 Carry out cardiopulmonary resuscitation and advanced life-support & 3.20 & 1.18 & 4.44 & 0.94 \\
\hline 6. 030 Write safe prescriptions for different types of drugs & 3.04 & 1.21 & 4.71 & 0.61 \\
\hline 7. 039 Administer oxygen therapy & 2.94 & 1.29 & 4.35 & 0.87 \\
\hline 8. 029 Work out drug dosage and record outcome accurately & 2.93 & 1.12 & 4.59 & 0.61 \\
\hline 9. 026 Interpret the results of commonly used investigations & 2.92 & 1.11 & 4.73 & 0.62 \\
\hline 10. 025 Interpret the findings from the history, the physical examination, and the mental-state examination & 2.83 & 1.11 & 4.76 & 0.59 \\
\hline 11. 042 Perform bladder catheterisation & 2.78 & 1.06 & 4.09 & 0.93 \\
\hline 12. 033 Give intravenous injections & 2.74 & 1.29 & 3.96 & 1.16 \\
\hline 13. 035 Carry out arterial blood sampling & 2.66 & 1.07 & 4.09 & 1.11 \\
\hline $\begin{array}{l}\text { 14. } 028 \text { Assess a patient's problems and form plans to investigate and manage these, involving patients in the } \\
\text { planning process }\end{array}$ & 2.61 & 1.07 & 4.55 & 0.75 \\
\hline 15. 027 Make clinical decisions based on the evidence they have gathered & 2.43 & 1.14 & 4.57 & 0.75 \\
\hline 16. 040 Use a nebuliser correctly & 2.39 & 1.36 & 3.95 & 1.10 \\
\hline 17. 034 Give intramuscular and subcutaneous injections & 2.25 & 1.16 & 3.55 & 1.29 \\
\hline 18. 038 Carry out basic respiratory function tests & 2.24 & 1.15 & 3.66 & 1.08 \\
\hline 19. 041 Insert a nasogastric tube & 1.95 & 1.04 & 3.61 & 1.17 \\
\hline 20. 036 Perform suturing & 1.92 & 1.00 & 3.29 & 1.20 \\
\hline
\end{tabular}

\footnotetext{
F1s, foundation year 1 doctors.
} 
Table 7 Preparedness of F1s in communication skills in rank order, and importance of each skill

\begin{tabular}{|c|c|c|c|c|}
\hline \multirow[b]{2}{*}{ Rank/item } & \multicolumn{2}{|c|}{ Preparedness } & \multicolumn{2}{|c|}{ Importance } \\
\hline & Mean & SD & Mean & SD \\
\hline $\begin{array}{l}\text { 1. } 043 \text { Communicate clearly, sensitively and } \\
\text { effectively with patients and their relatives }\end{array}$ & 3.71 & 0.95 & 4.69 & 0.60 \\
\hline $\begin{array}{l}\text { 2. } 044 \text { Communicate clearly, sensitively and } \\
\text { effectively with medical colleagues }\end{array}$ & 3.56 & 1.04 & 4.66 & 0.64 \\
\hline $\begin{array}{l}\text { 3. } 045 \text { Communicate clearly, sensitively and } \\
\text { effectively with nursing colleagues }\end{array}$ & 3.32 & 1.09 & 4.67 & 0.67 \\
\hline 4. 052 Breaking bad news & 2.86 & 1.181 & 4.26 & 0.89 \\
\hline $\begin{array}{l}\text { 5. } 054 \text { Communicating with people with mental } \\
\text { illness, including cases where patients have } \\
\text { special difficulties in sharing how they feel and } \\
\text { think with doctors }\end{array}$ & 2.59 & 0.97 & 4.10 & 0.78 \\
\hline 6. 053 Dealing with difficult and violent patients & 2.32 & 1.01 & 4.23 & 0.77 \\
\hline
\end{tabular}

F1s, foundation year 1 doctors.

between the results for question 77 and those for medical technical skills (question 31-42).

For questions 74/75 and questions 1-10, Spearman's $\rho=0.514, \quad p<0.0001$; for question 76 and question 23-42, $\rho=0.600$; for question 76 and questions 23-30, $\rho=0.571$, $p<0.0001$; for question 77 and questions $31-42, \rho=0.558$, $\mathrm{p}<0.0001$, significance is at the 0.01 level (two tailed) for all these pairings.

From the data in table 9, there was no statistically significant difference between the responses to question 79 and question 61 ( $\rho=0.727, p<0.0001$, significance is at the 0.01 level (two tailed)). For question 89 and question 67, the difference was statistically significant at $p=0.009(\rho=0.0319, p=0.012$, significance is at the 0.05 level (two tailed)).

\section{DISCUSSION}

The internal consistency across questions 1-73 (minus questions 48-50) was very high; only one question showed statistically significant differences between SpRs and consultants. The correlation between responses on curricular areas was positive and significant at the 0.01 level. Of the 70 items analysed which were drawn from Tomorrow's Doctors, 48 of them had mean scores of less than the midpoint of 3 . Taken together, this indicates that the average F1 was seen as unprepared for practice.

SpRs and consultants rated preparedness above the mid-point in only six out of 20 clinical and practical skills. F1s were

Table 8 Curricular themes and similar generic questions

\begin{tabular}{llc}
\hline Question/topic area & Mean & SD \\
\hline${ }^{*} 074 / 75$ Medical school has prepared them well in terms of & 3.42 & 0.91 \\
$\begin{array}{l}\text { theoretical and basic science knowledge (strongly agree 5 - } \\
\text { strongly disagree 1) }\end{array}$ & & \\
$\begin{array}{l}\text { 01-10 Scientific basis of practice (Tomorrow's Doctors: } \\
\text { preparedness 5/1) }\end{array}$ & 2.74 & 0.65 \\
$\begin{array}{l}\text { Q76 Medical school has prepared them well in terms of clinical } \\
\text { practice (strongly agree 5 - strongly disagree 1) }\end{array}$ & 2.87 & 1.15 \\
$\begin{array}{l}\text { 023-42 Clinical and practical skills (Tomorrow's Doctors: } \\
\text { preparedness 5/1) }\end{array}$ & 2.85 & 0.80 \\
$\begin{array}{l}\text { 023-30 Clinical skills (included in Tomorrow's Doctors clinical and } \\
\text { practical skills) (preparedness 5/1) }\end{array}$ & 0.98 & 0.91 \\
$\begin{array}{l}\text { Q77 Medical school has prepared them well to perform medical } \\
\text { technical skills (strongly agree 5 - strongly disagree 1) }\end{array}$ & 2.85 & 1.09 \\
$\begin{array}{l}\text { 031-42 Medical technical skills (included in Tomorrow's Doctors } \\
\text { clinical and practical skills) (preparedness 5/1) }\end{array}$ & 2.76 & 0.89 \\
\hline
\end{tabular}

${ }^{*}$ Scores for questions $74 / 75$ were averaged and the mean (SD) calculated.
Table 9 Topics and similar generic questions

\begin{tabular}{lcc}
\hline Question/topic area & Mean & SD \\
\hline $\begin{array}{l}\text { Q79 They are well prepared to seek help from more experienced } \\
\text { colleagues (strongly agree 5 - strongly disagree 1) }\end{array}$ & 4.04 & 0.85 \\
$\begin{array}{l}\text { Q61 Recognising personal and professional limits and willingness to } \\
\text { ask for help if necessary (Tomorrow's Doctors: preparedness 5/1) }\end{array}$ & 1.85 & 1.11 \\
$\begin{array}{l}\text { Q89 They have the confidence to question or even overrule a } \\
\text { decision concerning immediate patient management a senior }\end{array}$ & 2.47 & 1.02 \\
$\begin{array}{l}\text { colleague makes away from the patient (strongly agree 5 - strongly } \\
\text { disagree 1) }\end{array}$ & \\
$\begin{array}{l}\text { Q67 Dealing appropriately, effectively, and in patients' interests with } \\
\text { problems in the performance, conduct or health of colleagues }\end{array}$ & 2.30 & 1.05 \\
\begin{tabular}{l} 
(Tomorrow's Doctors: preparedness 5/1) \\
\hline
\end{tabular} & \\
\hline
\end{tabular}

deemed not well prepared for prescribing: "write safe prescriptions for different types of drugs" is the only item related to prescribing to be rated above the midpoint [at 3.04]. "Working out drug dosage and recording the outcome accurately" and "the safe use of medicine as a basis for prescribing" were rated at less than the midpoint. As approximately two-thirds of the F1s encountered by our respondents graduated from Nottingham University, the marked deficiencies in prescribing among Nottingham medical graduates found by English et $a l^{11}$ in the mid 1990s have barely improved, if at all.

Given the likely lack of experience of medical students outside of practice scenarios of breaking bad news, dealing with difficult and violent patients, and communicating with people with mental illness, the only point of note in these particular results is perhaps that they are so high. Tomorrow's Doctors ${ }^{2}$ demands that students have "opportunities to practise communicating in different ways" and the examples given include breaking bad news, dealing with difficult and violent patients, and communicating with people with mental illness. Against this background, it is very much open to question as to whether a new doctor can, or even should, be required to break especially bad news to patients or their relatives, still less whether he or she can arrive in their first job equipped so to do. Clearly, much depends on the kind of bad news involved and it is notable that the post-consultation draft of Tomorrow's Doctors ${ }^{31}$ gives no more detail on this than did the second edition of Tomorrow's Doctors. ${ }^{2}$ In contrast, even in those communications skills where medical students will inevitably have had lots of experience, there is not one in which they are, on average, well prepared.

The key generic questions that required respondents to agree or disagree with a statement rather than rate the level of preparedness correlated highly with the questions aggregated under the curricular themes from Tomorrow's Doctors, ${ }^{2}$ thus further reinforcing the reliability and internal consistency of the survey.

Our findings fit closely with other recent research, especially two studies broadly similar to ours, one based in the NorthWest area (Manchester) and one based in the West Midlands area (Birmingham), that surveyed educational supervisors and consultants, respectively, about the preparedness for practice of medical graduates in their first year of postgraduate training. ${ }^{12} 14$ As did Jones et al, ${ }^{12}$ our study found that medical graduates were best prepared in awareness of their limitations and in working in a team as well as in carrying out venepuncture and cardiopulmonary resuscitation, and least prepared in diagnosis and decision making, suturing and inserting a nasogastric tube. As did Wall et al, ${ }^{14}$ our research found that medical graduates were best prepared in team working and in communicating with relatives and colleagues as well as in history taking and in clinical examination, and least prepared in treatment, clinical 


\section{Main messages}

- Medical schools may not adequately prepare medical graduates for practice.

- More opportunities for experiential learning on the wards are needed during the final year of medical school.

- The perceived lack of preparedness of foundation year 1 doctors (F1s) is challenged by the lack of explicit criteria in the work based assessments.

- Explicit assessment criteria are needed which would require articulation of professional judgement.

- Although this is a study of primarily Nottingham graduates in the Trent Deanery area, it suggests further study to see if the situation depicted here is replicated elsewhere in the UK.

practical skills such as prescribing, and decision making. However, our study was more comprehensive and examined 70 topic areas/competencies outlined in Tomorrow's Doctors ${ }^{2}$ and an additional 18 generic questions, as opposed to 32 and 17 competencies (as in Jones et $a l^{12}$ and Wall et a ${ }^{14}$, respectively), drawn from those set out by the UK General Medical Council in The New Doctor. ${ }^{24} 25$

Important issues arise from our findings and those of other studies and these need to be addressed. Both SpRs and consultants perceive that the undergraduate medical degree has not adequately prepared F1s for practice, especially in clinical and practical skills. More opportunities for experiential learning on the wards are needed during the final year of medical school. Of course, the criteria by which SpRs and consultants judged the preparedness of new F1s are not known. There is a lack of specific criteria in Tomorrow's Doctors. ${ }^{2}$ While Tomorrow's Doctors ${ }^{2}$ lays out quite clearly what knowledge the new medical graduate must (not should) be able to demonstrate-and is quite precise in its description of the clinical and practical skills a medical graduate must be able to perform "safely and effectively" or the communication skills that a medical graduate must be able to demonstrate "clearly, sensitively and effectively" - what remains unclear is the extent to which the new graduate must be able to exercise the required skills and competencies and indeed under what conditions and other limits he or she can be expected to operate. SpRs and consultants may have inappropriate or unrealistic expectations made more likely by the lack of specific criteria in Tomorrow's Doctors. ${ }^{2}$ In addition, the perceived lack of preparedness of F1s is further challenged by the lack of explicit criteria in the work based assessments of the Foundation Programme that F1s must pass to gain full registration with the GMC. As a consequence of the lack of specific criteria, expectations about preparedness for practice at the undergraduate and postgraduate level are not aligned and the transition between medical graduate and first year junior doctor remains highly problematic.

Explicit assessment criteria are needed which would require articulation of professional judgement in both Tomorrow's Doctors $^{2}$ and in the work based assessments of the Foundation Programme. Although the GMC inspection satisfies itself as to the overall standard and content of undergraduate curricula, a national system of tests for medical undergraduates and hence uniform standards is perhaps needed, as Wass ${ }^{33}$ has previously argued, to ensure more aligned expectations about preparedness for practice and clinical competence of medical graduates.

\section{Suggestions for managing the transition from medical} school to F1

- Get specialist registrars (SpRs) and consultants to advise medical students and medical graduates more explicitly about what is expected of them as foundation year 1 doctors (F1s).

- Increase the likelihood of aligning expectations on the part of F1s and on the part of SpRs and consultants by having a set of competency levels in the form of specific criteria for the expected standards.

- Make sure that F1s share with the medical graduates who shadow them (or who attend a preparation for F1s preinduction and induction) what they have learnt from the first year of the Foundation Programme in terms of the things that they wished they had known when they started FY1

\section{Conclusion}

By its very nature, this has only been a partial survey of views of the preparedness for practice of F1 doctors in two teaching hospitals in England. Overall, although it would have been preferable to have a higher rate of return for consultants, the response rate was adequate, reasonable and fair, ${ }^{34.36}$ especially since the questionnaire sought a comprehensive view of preparedness in relation to the curricular outcomes of Tomorrow's Doctors ${ }^{2}$ and hence contained a large number of questions. The questionnaire was also anonymous and thus non-respondents could not be followed up, although attempts were made to contact all potential respondents several times. In addition, a substantial percentage of addresses were no longer valid: hard copies of questionnaires were returned unopened while emails bounced. The five point Likert scale may have led to a tendency to record the middle value where there was uncertainty in the mind of the respondent, and a six point or four point scale might be preferable for future studies. Also, in our research, the performance of F1s was assessed by overall impression and hence measured indirectly. Although there is a possible "halo effect" of rating on the basis of their overall impression (rather than specific aspects) of performance, it has been found unlikely to cause significant bias. ${ }^{37}$ Furthermore, overall impression and indirect measurement have been used by recent research similar to our own. ${ }^{12}{ }^{14}$

A concern of low return rates in surveys is response bias and consequent lack of generalisability of the findings because respondents differ from non-respondents. ${ }^{38}$ It has to be

\section{Current research questions}

- To explore what specialist registrars (SpRs), consultants, foundation year 1 doctors (F1s), and final year medical students understand by preparedness to practise.

- To examine the extent to which F1s are able to learn new skills quickly and adapt to new situations.

- To investigate the extent to which SpRs and consultants' stated perceptions of F1s coincide with how they assess the F1s in their compulsory formal assessments and with the rates of referral to the General Medical Council's Fitness to Practise committee.

- To gain a better understanding of how professional judgements are made. 
recognised that the present study is a snapshot of opinions in two hospitals in one area of England and that it discusses primarily graduates from one medical school. The snapshot nature is further underlined by around two thirds of respondents choosing not to indicate their specialism. However, response bias is of more importance in prevalence studies than in surveying views of senior colleagues about the preparedness for practice of junior colleagues. While it is possible that our respondents had stronger positive or negative views compared to non-respondents, this was mitigated by the high level of agreement in the views of SpRs and consultants and between the key generic questions and the questions from Tomorrow's Doctors. ${ }^{2}$ More importantly, the reliability and internal consistency of the data were statistically high.

The findings give cause for concern. SpRs and consultants perceived that the undergraduate medical degree had not adequately prepared F1s for practice, especially in clinical and practical skills. When items such as "recognising personal and professional limits and willingness to ask for help if necessary" and "seeking help from more experienced colleagues" obtain the highest ratings of preparedness, one needs to ask whether medical schools have gone too far in emphasising risk management and, perhaps inadvertently, helplessness.

Funding: East Midlands Healthcare Workforce Deanery.

\section{Competing interests: None declared.}

Ethics approval: Ethical approval was granted by the Derbyshire Local Ethics Committee (Unique Reference Number: 06/02401/137) and approval was also granted by the Research and Development Committee of Nottingham University Hospitals NHS Trust

Provenance and peer review: Not commissioned; externally peer reviewed.

\section{REFERENCES}

1. General Medical Council. Tomorrow's Doctors. London: GMC, 1993.

2. General Medical Council. Tomorrow's Doctors. London: GMC, 2003.

3. Hyde C, Agius S, Shacklady J, et al. How well prepared are newly-qualified doctors for Foundation Training? Issues and news on learning and teaching in medicine, dentistry and veterinary medicine 2007;1(15):10-11.

4. UK Foundation Programme Office. The Foundation Programme curriculum. Cardiff: UK Foundation Programme Office, 2009.

5. Flexner A. Medical education in the United States and Canada. New York: Carnegie Foundation for the Advancement of Higher Education, 1910.

6. Osler W. Principles and practice of medicine. New York: Appleton, 1892

7. Burch V, Nash R, Zabow T, et al. A structured assessment of newly qualified medical graduates. Med Educ 2005;39:723-731.

8. Moercke A, Eika B. What are the clinical skills levels of newly graduated physicians? Self-assessment study of an intended curriculum identified by a Delphi process. Med Educ 2002;36:478.

9. Prince K, Van Eijs $\mathrm{P}$, Boshuizen $\mathrm{H}$, et al. General competences of problem-based learning (PBL) and non -PBL graduates. Med Educ 2005;39:394-400.

10. Fraser R. Undergraduate medical education: present state and future needs. BMJ 1991;303:41-3.
11. English W, Nguyen-van-Tam J, Pearson J, et al. Deficiencies in undergraduate and pre-registration medical training in prescribing for pain control. Med Teach 1995; 17:215-8

12. Jones A, McArdle P, O'Neill P. How well prepared for the role of pre-regsitration house officer? A comparison of the perceptions of new graduates and educational supervisors. Med Educ 2001;35:578-84.

13. Jones A, McArdle P, O'Neill P. Perceptions of how well graduates are prepared for the role of pre-registration house officer: a comparison of outcomes from a traditional and an integrated PBL curriculum. Med Educ 2002;36:16-25.

14. Wall D, Boshaw A, Carolan J. From undergraduate medical education to preregistration house officer year: How prepared are students? Med Teach 2006;28:435-9.

15. Evans D, Roberts C. Preparation for practice. How can medical schools prepare better PRHOs? Med Teach 2006;28:549-52.

16. Lempp H, Seabrook M, Cochrane $M$, et al. Impact of educational preparation on medical students in transition from final year to $\mathrm{PRHO}$ year: a qualitative evaluation of final-year training following the introduction of a new year 5 curriculum in a London medical school. Med Teach 2004;26:276-8.

17. Watmough S, Garden A, Taylor D. Does a new integrated PBL curriculum with specific communication skills classes produce pre-registration house officers (PRHOs) with improved communication skills? Med Teach 2006;28:264-9.

18. Smith G, Poplett N. Knowledge of aspects of acute care in trainee doctors. Postgrad Med J 2002;78:335-8.

19. Lempp H, Seabrook M, Cochrane M, et al. The transition from medical student to doctor: perceptions of final year students and preregistration house officers related to expected learning outcomes. Int J Clin Prac 2005;59:324-9.

20. Tobaiqy M, McLay J, Ross S. Foundation year 1 doctors and clinical pharmacology and therapeutics teaching. A retrospective view in light of experience. $\mathrm{Br} \mathrm{J}$ Clin Pharm 2007:64:363-72.

21. Goldacre $\mathbf{M}$, Davidson J, Lambert T. The first house officer year: views of graduate and non-graduate entrants to medical school. Med Educ 2008;45:286-93.

22. Goldacre $\mathbf{M}$, Lambert T, Evans J, et al. Pre-registration house officers' views on whether their experience at medical school prepared them well for their jobs: national questionnaire survey. BMJ 2003;326:1011-2.

23. Watmough S, Taylor D, Garden A. Educational supervisors evaluate the preparedness for practice of graduates from reformed UK curriculum to work as pre-registration house officers (PRHOs): a qualitative study. Med Educ 2006:40:995-1001.

24. General Medical Council. The New Doctor. London: GMC, 1997

25. General Medical Council. The New Doctor. London: GMC, 2002.

26. Kunda Z, Fong G. Directional questions direct self-conceptions. J Exp Soc Psych 1993;29:63-86.

27. Cohen J. A Power primer. Psychol Bull 1992;112:155-1.

28. Jamieson S. Likert scales-how to (ab)use them. Med Educ 2004;38:1217-8.

29. Likert R. A Technique for the Measurement of Attitudes. Arch Psychol 1932;140:1-55

30. Bland M, Altman D. Statistics notes: Cronbach's alpha. BMJ 1997:314:572.

31. General Medical Council. Tomorrow's Doctors 2009 - post-consultation draft. London: GMC, 2009

32. General Medical Council. Tomorrow's Doctors: a draft for consultation. London: GMC, 2009.

33. Wass V. Ensuring medical students are 'fit for purpose'. BMJ 2005;331:791-2.

34. Cook C, Heath F, Thompson RL. A meta-analysis of response rates in web- or internet-based surveys. Educational and Psychological Measurement 2000:821-36.

35. Heberlein T, Baumgartner R. Factors affecting response rates to mailed questionnaires: a quantitative analysis of the published literature. Am Soc Rev 1978;43:447-62.

36. Lueddeke G, Anderson F, Carr N, et al. Looking back to the future: alumni perceptions of a UK undergraduate medical programme. Med Teach 2006;28:654-5.

37. Rolfe I, Andren J, Pearson S, et al. Clinical competence of interns. Med Educ 1995;29:225-30.

38. Armstrong D, Ashworth M. When questionnaire responses rates do matter: a survey of general practitioners and their views of NHS changes. Br J Gen Pract 2000;50:479-80. 


\section{PM How well prepared are medical students for their first year as doctors? The views of consultants and specialist registrars in two teaching hospitals}

C Matheson and D Matheson

Postgrad Med J 2009 85: 582-589

doi: 10.1136/pgmj.2008.071639

Updated information and services can be found at:

http://pmj.bmj.com/content/85/1009/582

These include:

Supplementary Material

References

Email alerting service
Supplementary material can be found at:

http://pmj.bmj.com/content/suppl/2009/11/03/85.1009.582.DC1.html

This article cites 28 articles, 6 of which you can access for free at: http://pmj.bmj.com/content/85/1009/582\#BIBL

Receive free email alerts when new articles cite this article. Sign up in the box at the top right corner of the online article.

\section{Notes}

To request permissions go to:

http://group.bmj.com/group/rights-licensing/permissions

To order reprints go to:

http://journals.bmj.com/cgi/reprintform

To subscribe to BMJ go to:

http://group.bmj.com/subscribe/ 